\title{
P09-02. Selection pressure of neutralizing antibodies and viral escape continues in late stages of the disease P Rusert*1, A Krarup ${ }^{1}$, B Joos ${ }^{1}$, T Uhr ${ }^{1}$, J Weber ${ }^{1}$, K Herbert ${ }^{2}$, HF Guenthard ${ }^{2}$ and A Trkola ${ }^{1}$
}

Address: ${ }^{1}$ Institute for Medical Virology, University of Zürich, Zürich, Switzerland and ${ }^{2}$ Division of Infectious Diseases, University Hospital Zürich, Zürich, Switzerland

* Corresponding author

from AIDS Vaccine 2009

Paris, France. 19-22 October 2009

Published: 22 October 2009

Retrovirology 2009, 6(Suppl 3):PII5 doi:I0.II86/I742-4690-6-S3-PII5

This abstract is available from: http://www.retrovirology.com/content/6/S3/PII5

(C) 2009 Rusert et al; licensee BioMed Central Ltd.

\section{Background}

The neutralizing antibody response against HIV is subject to constant viral escape. Viral escape from the autologous neutralization response has been documented during acute and chronic infection. Whether the successive adaptation between virus and antibody continues at the same rate at later disease stages, is yet not known.

\section{Methods}

Here we analyzed the neutralization response of a rapidly progressing, treatment naive individual over 1200 days from the first presentation in our clinic with documented acute infection until the patient's death. At 10 time points spread over the entire observation period virus full length envelope genes were cloned and sequenced. Altogether 26 envelope clones where obtained, analyzed for coreceptor tropism and susceptibility to autologous antibody neutralization in a pseudotyped virus inhibition assay.

\section{Results}

Analysis of plasma neutralization revealed an ongoing antibody driven HIV-1 envelope evolution during the entire disease course including the late symptomatic phase. We found evidence for a strong selection pressure on the V1/V2 loop based on the synonymous/nonsynonymous mutation ratios throughout the entire observation period, while the mutation rate within the V3 loop only increased at later stages. Plasma antibodies were at all time points capable of neutralizing preceding but not cur- rent viral quasispecies, indicating that despite rapid CD4 decline ( $<200$ past day 900) the humoral immune response was functional and capable of adapting to new emerging strains. For a brief period around day 900 a X4 using variant emerged that was completely resistant to the antibodies from earlier time points but controlled subsequently.

\section{Conclusion}

Our study provides strong evidence that coevolution of the viral envelope and antibody response against HIV-1 continues during all disease stages, and that the humoral immune response is surprisingly apt to react to newly evolving quasispecies even when CD4 T cells have dramatically declined. 